\title{
Synthesis, Characterization and Antimicrobial Screening of Coumarin Copolymers
}

\author{
R. CHITRA ${ }^{1}$, E. KAYALVIZHY ${ }^{1}$, P. JEYANTHI ${ }^{2}$ and P. PAZHANISAMY ${ }^{3 *}$ \\ ${ }^{1}$ Research and Development Centre, Bharathiar University, Coimbatore, India \\ ${ }^{2}$ Department of Chemistry, Bharathi Women's College, Chennai-600108, India \\ ${ }^{3}$ Department of Chemistry, Sir Theagaraya College, Chennai-600021, India \\ p_pazhanisamy@yahoo.com
}

Received 30 August 2012 / Accepted 19 September 2012

\begin{abstract}
Acryloyloxy-4-methylcoumarin (ACU) monomer was polymerized with $N$-cyclohexylacrylamide (NCA) in different feed ratio using AIBN (Azobisisobutyronitrile) as initiator in DMF. The copolymers were characterized by ${ }^{1} \mathrm{H}$ NMR spectroscopy and the copolymer compositions were determined by ${ }^{1} \mathrm{H}$ NMR analysis. The reactivity ratios of monomers were determined using linear methods like Fineman-Ross and Kelen-Tudos. The value showed that ACU is more reactive than NCA. The copolymers contained a higher proportion of ACU units. Mean sequence lengths of copolymers were estimated from $r_{1}$ and $r_{2}$ values. ACU unit increases in a linear fashion in the polymer chain as the concentration of ACU increases in the monomer feed. The copolymers were tested for their antimicrobial properties against selected microorganisms.
\end{abstract}

Keywords: 7-Acryloyloxy-4-methylcoumarin, $N$-Cyclohexylacrylamide, Reactivity ratio, Mean sequence length, Antimicrobial activity

\section{Introduction}

Coumarins are plant flavonoids widely distributed in nature. Coumarins (2H-1-bengopyran2-ones) are important oxygen containing fused heterocycles used in drugs and dyes ${ }^{1}$. Coumarins be bound their class name to 'coumarou' the vernacular name of the Tonka bean (Dipteryxodorata willd, Fabaceae), from which coumarin itself was isolated in $1820^{2}$. They are the family of lactones containing benzopyrone skeletal framework that have enjoyed isolation from plant as well as total synthesis in the laboratory. The extract containing coumarin related heterocycles which were employed as herbal remedies in early days, have now been extensively studied for their biological activities ${ }^{3}$. The incorporation group as a fused component into parent coumarin alters the property of parent coumarin and converts it into a more useful product ${ }^{4}$ natural coumarins are known to have antidiabetic activity ${ }^{5}$, anabolic antioxidant and hepato protective activities ${ }^{6}$. Substituted coumarins derivatives have been reported to have variety of biological activities. The potent antibiotics like novobiocin, coumaromycin and chartesium are coumarin derivatives. 
One method of achieving antimicrobial polymers is the preparation of polymerizable monomers containing biocide moieties and then polymerizing subsequently or copolymerizing with another monomer ${ }^{7-10}$. Coumarin polymers have not received considerable attention in the literature. However, the reported coumarin polymers possess variety of functions and appear to be interesting. Although there are a huge number of reports on monomeric coumarin derivatives, there are only a few reports on coumarin polymers $^{11,12}$. Bhrahmbhatt et al. prepared poly (3-phenoxycoumarin ethylene) and determined their toxicity effect on various fungal and bacterial strains ${ }^{13}$. These polymers showed good biological activity. Lee and co-workers ${ }^{14}$ prepared Coumaryl acrylate and further they synthesized poly (cinnam-4'-yl methyl methacrylate). They investigated optical anisotropy using UV-Vis spectrometer and also studied the thermal stability of polymer films as photo alignment layer. Huyck et al. have synthesized coumarin functionalized poly (alkyl acrylate) and poly(alkyl methacrylate) random copolymers and studied the influence of copolymer composition on photocross-linking ${ }^{15}$. Lindsay and co-workers ${ }^{16}$ synthesized the copolymerization of coumarin methacrylate with isobornyl methacrylate. These polymers showed tremendous non-linear optical properties. There are reports on the antifungal activities on monomeric coumarin, although works on coumarin polymers are rare. Since, coumarin and its derivatives have attracted considerable interest because of various physiological and biochemical properties, our interest was to synthesize acrylic copolymers with 4- methyl coumarin side groups. This work was taken up with a view to synthesizing biocidal polymers, derived from acrylic monomers as these polymers have many commercial applications.

The synthesis and development of antimicrobial polymers is one of the leading frontiers of research in polymer science. With this view, in our earlier work ${ }^{17} \mathrm{~N}$-cyclohexylacrylamide was copolymerized with 8-quinolinyl acrylate. Copolymers with different feed ratio were prepared and characterized by ${ }^{1} \mathrm{H}-\mathrm{NMR}$ spectroscopy. The reactivity ratios of monomers determined by Fineman-Ross $\left(r_{1}=0.84\right.$ and $\left.r_{2}=2.86\right)$, Kelen-Tudos $\left(r_{1}=0.84\right.$ and $r_{2}=2.82$ ). The $r_{1} \cdot r_{2}=2.42$ value indicates the formation of random copolymers. The thermal stability decreases with increasing mole \% of 8QA. It shows antimicrobial activity. The activity of copolymers against Fungi (A.N and A.F) increases with increasing mole \% of NCA.

In this paper, we report the synthesis of $N$-cyclohexylacrylamide (NCA) and 7-acryloyloxy4-methylcoumarin (ACU) copolymers in different feed ratio by free radical polymerization. The prepared copolymers were characterized by ${ }^{1} \mathrm{H}$ NMR spectroscopy. Copolymer composition was obtained from ${ }^{1} \mathrm{H}$ NMR data monomer reactivity ratios were determined by FinemanRoss $^{18}$ and Kelen-Tudos ${ }^{19}$ methods. The prepared copolymers were characterized by calculating its reactivity ratio; mean sequence length, antibacterial and antifungal studies.

\section{Experimental}

The monomer $\mathrm{N}$-cyclohexylacrylamide was prepared by the reaction of cyclohexanol with acrylonitrile. $N$-cyclohexylacrylamide was recrystallized in warm dry benzene. The white crystals have mp. $115^{\circ} \mathrm{C}$ and the yield was $87 \%{ }^{20}$. The monomer was confirmed by ${ }^{1} \mathrm{H}$ NMR spectroscopy (Figure 1).

\section{Synthesis of 7-hydroxy-4-methylcoumarin and acryloyl chloride}

7-Hydroxy-4-mehtylcoumarin and acryloyl chloride were prepared according to the process reported in the literature ${ }^{21,22}$. 


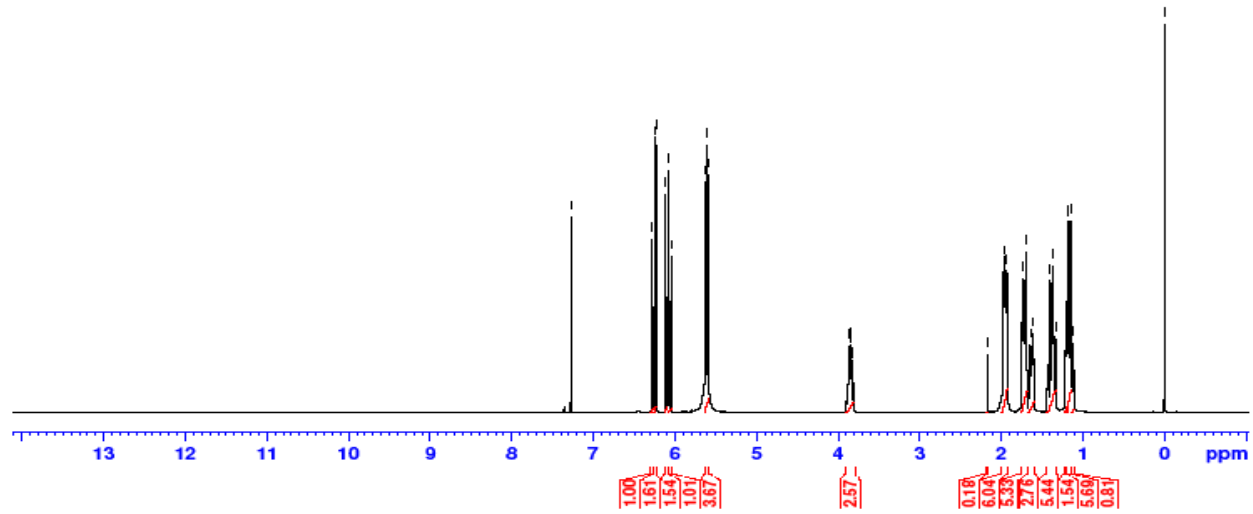

Figure 1. ${ }^{1} \mathrm{H}$-NMR spectrum of $N$-cyclohexylacrylamide

\section{Synthesis of 7-hydroxy-4-methylcoumarin}

$250 \mathrm{~mL}$ of concentrated sulphuric acid $\left(\mathrm{H}_{2} \mathrm{SO}_{4}\right)$ was added to a one liter three necked flask fitted with a thermometer, mechanical stirrer and a dropping funnel. The flask was immersed in an ice bath. Solution containing $(0.23 \mathrm{~mol})$ of resorcinol and $(0.26 \mathrm{~mol})$ of ethyl acetoacetate was added drop wise to the flask maintained at temperature less than $10{ }^{\circ} \mathrm{C}$ with constant stirring. The reaction mixture was kept for about 18 hours at room temperature after completion of addition of the reagents. The contents of the flask were poured into crushed ice-water mixture where the product separated out.

\section{Synthesis of acryloyl chloride}

A mixture of acrylic acid (1 mol), Benzoyl chloride $(2 \mathrm{~mol})$ and hydroquinone $(0.0025 \mathrm{~mol})$ was distilled at a fairly high rate through an efficient column. The distillate was collected in a receiver containing hydroquinone $(0.0025 \mathrm{~mol})$. The product was obtained at a temperature between $85-100{ }^{\circ} \mathrm{C}$. The crude product was redistilled through the same column.

\section{Synthesis of 7-acryloyloxy-4-methylcoumarin}

To a $1 \mathrm{~L}$ three-necked flask equipped with stirrer, thermometer and guard tube were added absolute alcohol $(550 \mathrm{~mL})$ and $\mathrm{NaOH}(4 \mathrm{~g}, 0.1 \mathrm{~mol})$ and the contents were stirred until all $\mathrm{NaOH}$ was dissolved. Then, 7-hydroxy-4-methyl coumarin $(17.62 \mathrm{~g}, 0.1 \mathrm{~mol})$ was added to the above solution. The reaction mixture was heated to $60{ }^{\circ} \mathrm{C}$ for $30 \mathrm{~min}$. with stirring, then cooled to room temperature and then to $0-5{ }^{\circ} \mathrm{C}$. Freshly prepared acryloyl chloride $(9.2 \mathrm{~mL}$, $0.11 \mathrm{~mol}$ ) was added drop wise within $60 \mathrm{~min}$ to the cooled reaction mixture. The temperature was maintained around $0-5{ }^{\circ} \mathrm{C}$ during the addition. After complete addition, reaction mixture was stirred for $90 \mathrm{~min}$ and it was poured into crushed ice water mixture where a white colored product was separated (Figure 2). It was filtered, dried and recrystallized from methanol. $\mathrm{mp}: 122^{\circ} \mathrm{C}$. Yield: $89 \%$. 
IR $\left(\mathrm{KBr}, \mathrm{cm}^{-1}\right)$ : 3073(-CH stretching vibration of the aromatic ring), 2986 (CH3), 1737 (broad, $\mathrm{C}=\mathrm{O}$ of acrylate and of coumarin moiety), $1630(\mathrm{C}=\mathrm{C}), 1240$ (asymmetric $\mathrm{C}-\mathrm{O}-\mathrm{C})$, 1142 (symmetric C-O-C), 890 (-CH bending mode of vinyl group), 730 (rocking mode of vinyl group). ${ }^{1} \mathrm{H}-\mathrm{NMR}(\delta \mathrm{ppm}): 6.26(1 \mathrm{H},-\mathrm{CH}=), 2.43(3 \mathrm{H}, \mathrm{CH} 3), 6.36(2 \mathrm{H}$, nonequivalent methylene protons), 7.06-7.72 (3H, aromatic protons).<smiles>Cc1cc(=O)oc2cc(O)ccc12</smiles>

7- Hydroxy-4-methylcoumarin<smiles>C=CC(=O)Cl</smiles>

Acryloyl chloride

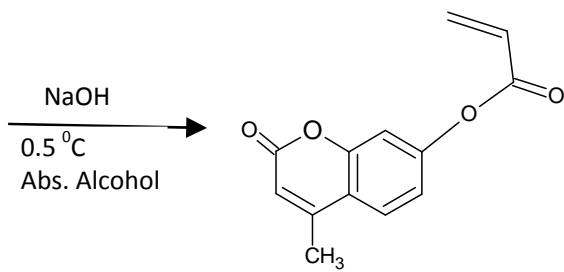

7- Acryloyloxy-4-methylcoumarin

Figure 2. Synthesis of 7-acryloyloxy-4-methylcoumarin

\section{Copolymerization}

A total feed of $5 \mathrm{~g}$ of monomers $N$-cyclohexylacrylamide, 7-acryloyloxy-4-methyl coumarin and $50 \mathrm{mg}$ of AIBN initiator were dissolved in $25 \mathrm{~mL}$ of DMF placed in a standard reaction tube to obtain a homogenous solution. The mixture was flushed with oxygen free dry nitrogen gas. The reaction vessel is then immersed in a thermostatic water bath maintained at $60{ }^{\circ} \mathrm{C}$. The copolymerization reaction was allowed to proceed for an appropriate duration that would give a conversion below $10 \%$. The solution poured in ice cold water to precipitate the copolymer and the copolymer washed with methanol to remove unreacted monomers. It was then dried in vacuum oven for 24 hours.

\section{Antimicrobial assay}

Antimicrobial analysis was followed using standard agar well diffusion method to study the antimicrobial activity of compounds ${ }^{24-26}$. Each bacterial and fungal isolate was suspended in Brain Heart Infusion (BHI) broth and diluted to approximately $10^{5}$ colony forming unit (CFU) per $\mathrm{mL}$. They were flood-inoculated onto the surface of BHI agar and then dried. Five-millimeter diameter wells were cut from the agar using a sterile cork-borer and $30 \mu \mathrm{L}$ ( $5 \mu \mathrm{g}$ compound in $500 \mu \mathrm{L}$ DMSO) of the sample solution were poured into the wells. The plates were incubated for $18 \mathrm{~h}$ at $37^{\circ} \mathrm{C}$ for bacteria and at room temperature for fungi. Antimicrobial activity was evaluated by measuring the diameter of the zone of inhibition in $\mathrm{mm}$ against the test microorganisms. DMSO was used as solvent control. Ciprofloxacin was used as reference antibacterial agent. Ketoconazole was used as reference antifungal agent. The tests were carried out in triplicates.

\section{Results and Discussion}

The schematic representation of the copolymer is given below (Figure 3):<smiles>C=CC(=O)NC1CCCCC1</smiles><smiles>C=CC(=O)Oc1ccc2c(C)cc(=O)oc2c1</smiles>

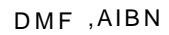




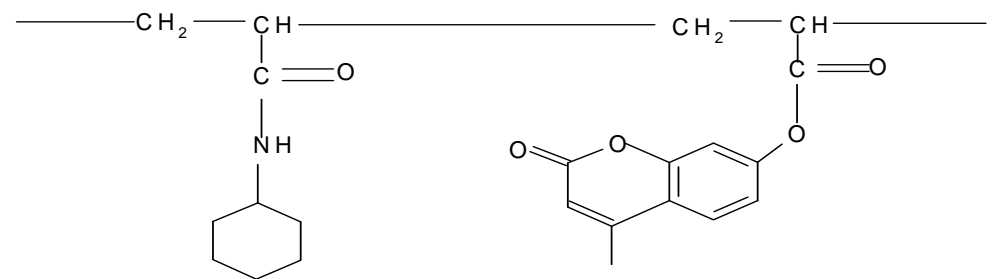

Figure 3. Copolymerization of NCA and ACU

\section{Characterization of copolymer}

The ${ }^{1} \mathrm{H}$ NMR spectrum of copolymer, poly (NCA-co-ACU) (0.8: 0.2) is shown in Figure 4 and the following peaks appear in the copolymer spectrum; at 1.14 -2.96 ppm for cyclohexyl $\mathrm{CH}_{2}$ group, at $3.68 \mathrm{ppm}$ for backbone $\mathrm{CH}_{2}$, at 7.07-8.01 ppm due to ACU aromatic protons.

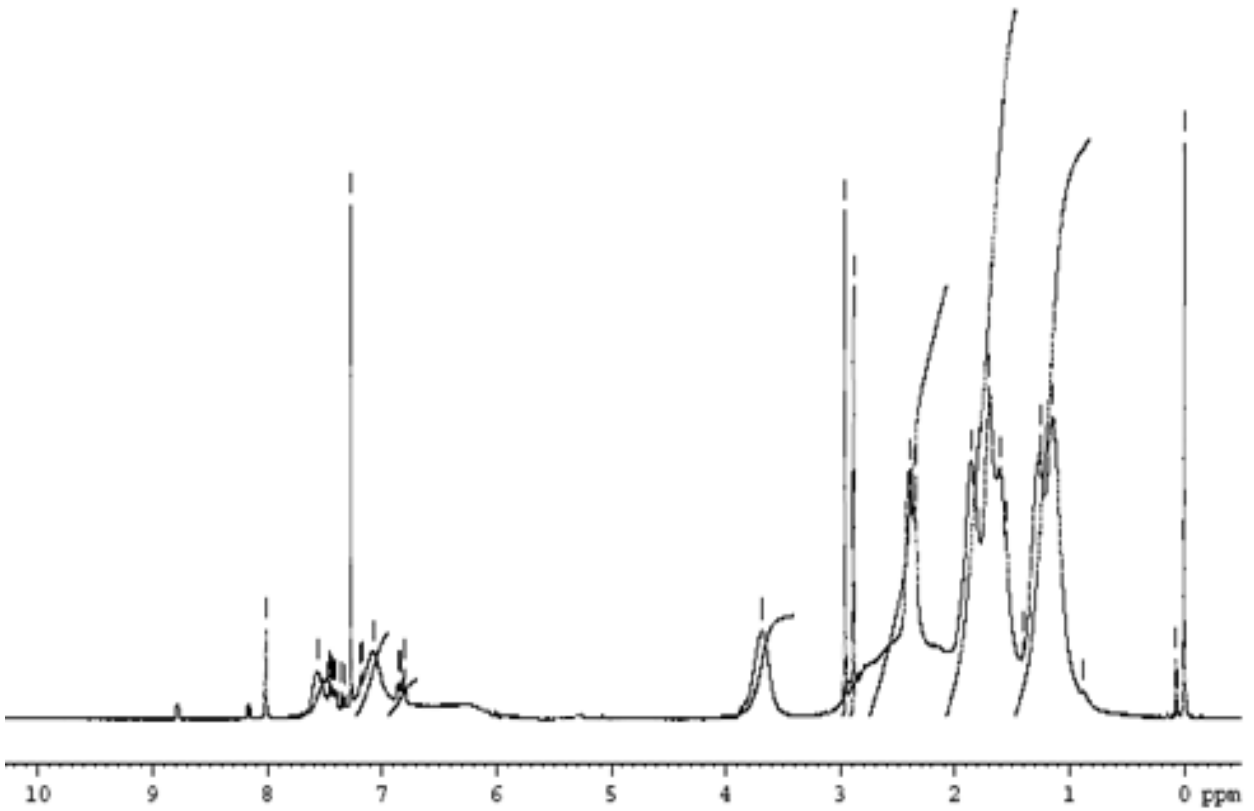

Figure 4. ${ }^{1} \mathrm{H}$ NMR spectrum of poly (NCA-co-ACU) (0.8: 0.2)

\section{Determination of copolymer composition}

The copolymer composition was determined by ${ }^{1} \mathrm{H}$ NMR spectral analysis of the copolymer. The assignment of the resonance peaks in the ${ }^{1} \mathrm{H}$ NMR spectrum allows the accurate evaluation of the content of each kind of monomer incorporated into the copolymer chain. The area of coumarin moiety was used to determine the copolymer composition. Resonance signal at 7.07-8.01 ppm corresponds to aromatic proton, and their integrated intensity of this peak is compared to the total intensities of all the peaks in the copolymer spectrum, which is a measure of their relative areas. The copolymer compositions can be obtained using;

$$
\mathrm{X}_{\mathrm{ACU}}=\frac{15 \mathrm{~A}(\text { aryl })}{3 \mathrm{~A}_{\text {total }}+5 \mathrm{~A}(\operatorname{aryl})}
$$

Where $\mathrm{X}=$ mole fraction and $\mathrm{A}=$ peak area. 


\section{Reactivity ratios}

From the monomer feed ratios and the resultant copolymer compositions, the reactivity ratios of monomer 1 (NCA) and monomer 2 (ACU) were evaluated by the methods of Fineman-Ross (FR ) and Kelen- Tudos (KT). The significant parameters of F-R and K-T and equation are presented in Table 1. The reactivity ratios for NCA $\left(r_{1}\right)$ and ACU $\left(r_{2}\right)$ from the F-R plot (Figure 5) and K-T (Figure 6) plot are given in Table 2. The value of $r_{1}$ is less than 1 and $r_{2}$ is greater than $1 . r_{1}$ shows that NCA favors cross-propagation as opposed to homopropagation and $r_{2}$ shows that ACU favors homopropagation over cross-propagation. The $r_{1}, r_{2}=1.4$ value indicates the formation of random copolymers.

Table 1. Finemann-ross and Kelen-tudos parameters for the copolymers

\begin{tabular}{|c|c|c|c|c|c|c|c|c|}
\hline 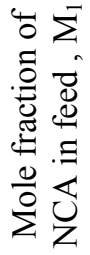 & 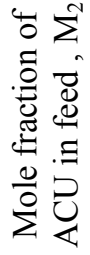 & 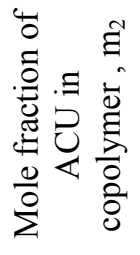 & $\sum_{\substack{\| \\
\text { II }}}^{\sum_{1}^{N}}$ & 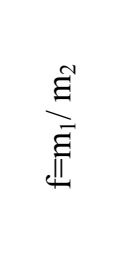 & 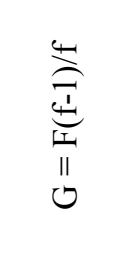 & $\frac{4}{1}$ & 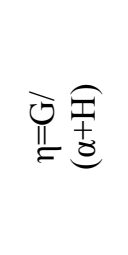 & 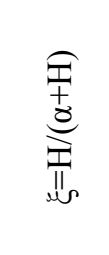 \\
\hline 0.2 & 0.8 & 0.8757 & 0.25 & 0.1419 & -1.51 & 0.4404 & -0.7284 & 0.2124 \\
\hline 0.3 & 0.7 & 0.7913 & 0.427 & 0.2637 & -1.1922 & 0.6914 & -0.5131 & 0.2976 \\
\hline 0.4 & 0.6 & 0.6874 & 0.667 & 0.4547 & -0.7999 & 0.9784 & -0.3066 & 0.3748 \\
\hline 0.5 & 0.5 & 0.5468 & 1 & 0.8288 & -0.2065 & 1.2065 & -0.0727 & 0.4251 \\
\hline 0.6 & 0.4 & 0.4362 & 1.5 & 1.2925 & 0.3394 & 1.7408 & 0.1006 & 0.5161 \\
\hline 0.7 & 0.3 & 0.3899 & 2.333 & 1.5647 & 0.8419 & 3.4785 & 0.1647 & 0.6807 \\
\hline 0.8 & 0.2 & 0.2743 & 4 & 2.6456 & 2.4881 & 6.0477 & 0.3239 & 0.7875 \\
\hline
\end{tabular}

$\alpha=\left(H_{\min } X H_{\max }\right)^{1 / 2}=1.6391$

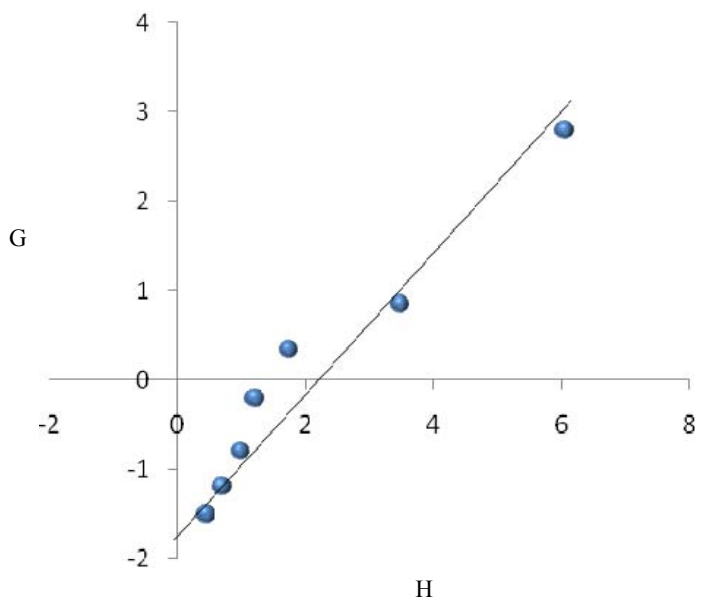

Figure 5. Fineman-Ross plot of Poly ( NCA-co-ACU)

Table 2. Copolymerization parameter for the NCA $\left(r_{1}\right)$ and ACU $\left(r_{2}\right)$

\begin{tabular}{cccc}
\hline Methods & $\mathrm{r}_{1}$ & $\mathrm{r}_{2}$ & $\mathrm{r}_{1} \cdot \mathrm{r}_{2}$ \\
\hline Fineman-Ross (FR) & 0.80 & 1.75 & 1.40 \\
Kelen-Tudos (KT) & 0.85 & 1.75 & 1.49 \\
\hline
\end{tabular}




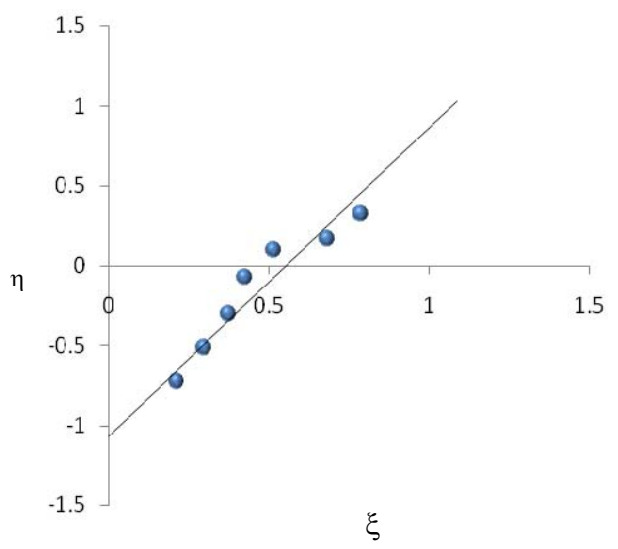

Figure 6. Kelen-Tudos plot of poly (NCA-co-ACU) mean sequence length The mean sequence length ${ }^{23}$ can be determined using the pertinent equations;

$$
\begin{aligned}
& l_{1}=r_{1} \frac{M_{1}}{M_{2}}+1 \\
& l_{2}=r_{2} \frac{M_{2}}{M_{1}}+1
\end{aligned}
$$

Where $r_{1}$ and $r_{2}$ are the reactivity ratios and $M_{1}$ and $M_{2}$ represent the concentration of NCA and ACU respectively, in the monomer feed. The mean sequence lengths of copolymers are given in Table 3. It is significant to note from Table 3 that the ACU units increases in a linear fashion in the polymer chain as the concentration of ACU increases in the feed.

Table 3. Mean sequence lengths in (NCA-co-ACU)

\begin{tabular}{ccccc}
\hline $\begin{array}{c}\text { Mole fraction of } \\
\text { ACU in feed } \mathrm{M}_{2}\end{array}$ & $1_{1}$ & $1_{2}$ & $1_{1}: 1_{2}$ & Distribution \\
\hline 0.8 & 1.2 & 8 & $1: 8$ & N CCCCCCCCN \\
0.7 & 1.3 & 5 & $1: 5$ & NCCCCCN \\
0.6 & 1.5 & 3.6 & $2: 4$ & NNCCCCNN \\
0.5 & 1.8 & 1.75 & $2: 2$ & NNCCNN \\
0.4 & 2.2 & 2.1 & $2: 2$ & NNCCNN \\
0.3 & 2.8 & 1.75 & $3: 2$ & NNNCCNNN \\
0.2 & 4.2 & 1.43 & $4: 1$ & NNNNCNNNN \\
\hline \multicolumn{5}{c}{$N=N C A ; C=A C U$}
\end{tabular}

\section{Antimicrobial activities}

The results of antibacterial activities (Figure $7 \& 8$ ) of copolymers were shown in Table 4 and Table 5. The activity of copolymers against bacteria and fungi increases with increasing mole $\%$ of NCA. All the three copolymers impart almost similar activity against all the three bacteria. The polymers showed higher activity than the reference against in all the three bacteria. From the Table 5, it is observed that the activity of copolymers against the fungi increases with increasing amount of NCA feed. When the content of NCA at 0.7 mole fraction, the polymers showed strong inhibitory effect against Aspergillus niger and Candida tropicalis. 
Table 4. Antibacterial study of copolymers (values in mm)

\begin{tabular}{clccc}
\hline S.No & Compounds & Escherichia coli & Salmonella typhi & Bacillus cereus \\
\hline 1. & $\begin{array}{l}\text { ACU-NTC } \\
(0.3: 07)\end{array}$ & 19 & 18 & 19 \\
2. & $\begin{array}{l}\text { ACU-NTC } \\
(0.5: 05)\end{array}$ & 18 & 16 & 17 \\
3. & $\begin{array}{l}\text { ACU-NTC } \\
(0.7: 03)\end{array}$ & 11 & 11 & 11 \\
4. & Ciprofloxacin & 10 & 23 & 32 \\
\hline
\end{tabular}

Table 5. Anti fungal study of copolymers (values in $\mathrm{mm}$ )

\begin{tabular}{ccccc}
\hline S.No & Compounds & Aspergillus niger & Candida albicans & Candida tropicalis \\
\hline 1. & $\begin{array}{c}\text { ACU-NTC } \\
(0.3: 07)\end{array}$ & 28 & 18 & 26 \\
2. & $\begin{array}{c}\text { ACU-NTC } \\
(0.5: 05)\end{array}$ & 25 & 14 & 23 \\
3. & ACU-NTC & 06 & 13 & 07 \\
4. & Ketoconazole & 26 & 24 & 30 \\
\hline
\end{tabular}

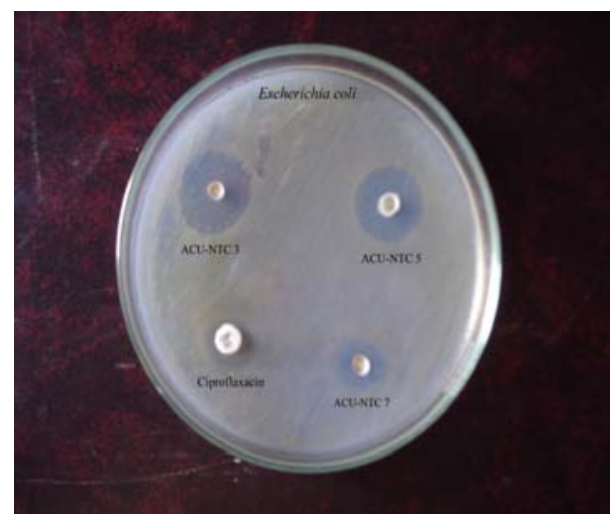

Figure 7. Antibacterial activity of NCAACU copolymers against E.coli

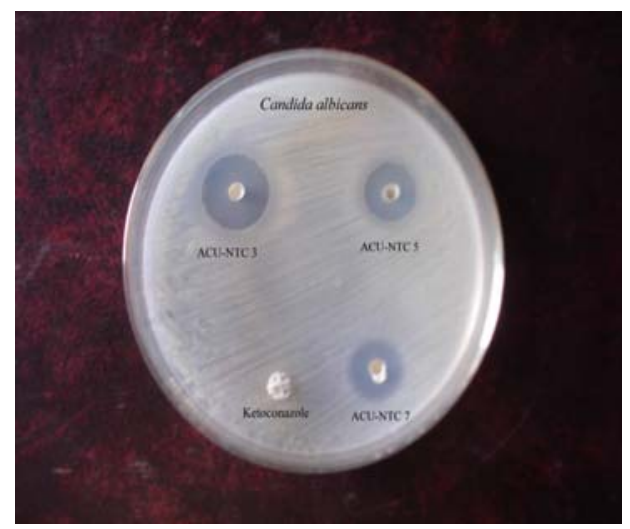

Figure 8. Anti fungal activity of NCAACU copolymers against C.albicans

\section{Conclusion}

Copolymers of $\mathrm{N}$-cyclohexylacrylamide and 7-Acryloyloxy-4-methylcoumarin in various feed ratio prepared were characterized by ${ }^{1} \mathrm{H}$ NMR method. The reactivity ratios of the monomers calculated by Finemann-Ross and Kelen-Tudos methods indicate that the copolymers are random copolymers. Calculation of mean sequence lengths showed that the ACU units increases in a linear fashion in the polymer chain as the concentration of ACU increases in the feed. The organisms antifungal activity was carried out by using Aspergillus flavus, Candida albicans and Candida tropicalis. The antibacterial activity was carried out by using Escherichia coli, Salmonella typhi and Bacillus cereus. It was observed from the results the both antibacterial and antifungal activity increases with increase in the concentration of NCA moiety. 


\section{References}

1. Rajasekaran S, Rao Gopal Krishna, Pai Sanjay P N and Ranjan Amit, Int $J$ Chem Tech Res., 2011, 3(2), 555-559.

2. Dighe Nachiket S, Patton Shashikant R, Dengale Santosh S, Musmade Deepak S, Shelar Madhuri, Tambe Vishal and Hole Mangesh B, Der Pharma Chemica, 2010, 2(2), 65-71.

3. Ajani Olayinka O. and Nwinyl Obinna C, J Heterocycl Chem., 2010, 47, 179-187.

4. Brahmbhatt D I, Gajera J M, Pandya V P and Patel M A, Indian J Chem., 2007, 46(B), 869-871.

5. Sharma Rohini and Arya Vikrant, J Chem Pharm Res., 2011, 3(2), 204-212,

6. Murrey R D H, Medez D and Brown S A, The Natural Coumarins Occurrences, Chemistry and Biochemistry, John Wiley Interscience, Newyork, 1982.

7. Kanazawa A, Ikeda T and Endo T, J Polym Sci A Polym Chem., 1993, 31, 1467-1472.

8. Patel M M, Kapadia M A, Patel G P and Joshi J D, Iran Polym J., 2007, 16, 113-122.

9. Patel M V, Patel R M, Patel J N and Dolia M B, Iran Polym J., 2005, 14(10), 899-908.

10. Bankova M, Petrova T, Manolova N and Rashkov I, Eur Polym J., 1996, 32, 569-578.

11. Ren B, Zhao D, Liu S, Liu X and Tong Z, Macromolecules, 2007, 40, 4501-4508.

12. Kim C, Trajkovska A, Wallace J U and Chen S H, Macromolecules, 2006, 39(11), 3817-3823.

13. Brahmbhatt D I, Singh S and Patel K C, Euro Poly J., 1999, 35(2), 317-324.

14. Lee J, Kim H and Kim H, Bull Korean Chem Soc., 2001, 22, 179-182.

15. Huyck R H, Trenor S R, Love B J and Long T E, J Macromol Sci A Pure Appl Chem., 2008, 45(1), 9-15.

16. Lindsay G A, Henry R A and Hoover J M, Near Poly Prepr (Amer Chem Soc Div Poly Chem.), 1993, 34, 771-771.

17. Chitra R, Jeyanthi P and Pazhanisamy P, Int J Chem Tech Res., 2010, 2(4), 1871-1880.

18. Fineman M and Ross S D, J Poly Sci., 1950, 5(2), 259.

19. Kelen T and Tudos F, J Macromol Sci Chem., 1975, A9, 1.

20. Pazhanisamy P and Reddy B S R, eXPRESS Poly Lett., 2007, 1(11), 740-747.

21. Brain S, Furniss AJ, Hannaford P W, Smith G and Tatchell A R, Vogel's textbook of Practical Organic Chemistry; $5^{\text {th }}$ Eds., Pearsion Education Pvt. Ltd. Singpore, 1989, 1193.

22. Stempel G H, Cross R P and Mariella R P, J Am Chem Soc., 1950, 72, 2299-2300.

23. Pazhanisamy P and Reddy B S R, eXPRESS Poly Lett., 2007, 1(6), 391-396.

24. Perez C, Pauli M and Bazerque P, Acta Biol Med Exp., 1990, 15, 113-115.

25. Erdemog $7 \mathrm{lu}$ N, Ku Peli E, Yes E and Ilada R, J Ethnopharmacol., 2003, 89, 123-131.

26. Bagamboula C F, Uyttendaele M and Debevere J, Food Microbiol., 2004, 21(1), 33-42. 